\title{
Radiation Gene-expression Signatures in Primary Breast Cancer Cells
}

\author{
LUIGI MINAFRA ${ }^{1 *}$, VALENTINA BRAVATÀ ${ }^{1 *}$, FRANCESCO P. CAMMARATA ${ }^{1}$, \\ GIORGIO RUSSO $^{1}$, MARIA C. GILARDI ${ }^{1,2}$ and GIUSI I. FORTE ${ }^{1}$ \\ ${ }^{1}$ Institute of Molecular Bioimaging and Physiology, National Research Council (IBFM-CNR), Cefalù, Italy; \\ ${ }^{2}$ Nuclear Medicine Unit, San Raffaele Scientific Institute, Milan, Italy
}

\begin{abstract}
Background/aim: In breast cancer (BC) care, radiation therapy $(R T)$ is an efficient treatment to control localized tumor. Radiobiological research is needed to understand molecular differences that affect radiosensitivity of different tumor subtypes and the response variability. The aim of this study was to analyze gene expression profiling $(G E P)$ in primary $B C$ cells following irradiation with doses of $9 G y$ and 23 Gy delivered by intraoperative electron radiation therapy (IOERT) in order to define gene signatures of response to high doses of ionizing radiation. Materials and Methods: We performed GEP by cDNA microarrays and evaluated cell survival after IOERT treatment in primary $B C$ cell cultures. Real-time quantitative reverse transcription polymerase chain reaction ( $q R T-P C R)$ was performed to validate candidate genes. Results: We showed, for the first time, a 4-gene and a 6-gene signature, as new molecular biomarkers, in two primary BC cell cultures after exposure at 9 Gy and 23 Gy respectively, for which we observed a significantly high survival rate. Conclusion: Gene signatures activated by different doses of ionizing radiation may predict response to $R T$ and contribute to defining a personalized biological-driven treatment plan.
\end{abstract}

Breast cancer (BC) recovery has considerably increased thanks to the advances achieved from research in this field. However, despite the important results obtained, $\mathrm{BC}$ remains a complex multifactorial disease with distinct subtypes

*These Authors contributed equally to this study.

Correspondence to: Valentina Bravatà, Ph.D., IBFM-CNR SS Cefalù, Contrada Pietrapollastra-Pisciotto, 90015 Cefalù (PA), Italy. Tel: +39 0921920612, Fax: +39 0921920510, e-mail: valentina bravata@ibfm.cnr.it

Key Words: Ionizing radiation, Intraoperative electron radiation therapy, primary breast cancer cells, gene signatures. associated with different outcomes. Many therapeutic options, such as surgery, endocrine therapy, chemotherapy and radiation therapy (RT), often used in combination, have been developed to treat BC. RT is an efficient treatment for controlling a localized tumor and is often used as the last chance for patients with inoperable cancer or the first choice in the case of incompletely resected or recurrent tumor after surgery (1-3). Today, more than $50 \%$ of patients with cancer, including those with $\mathrm{BC}$, receive $\mathrm{RT}$ through several modalities, such as external beam RT, intraoperative electron radiation therapy (IOERT), or internal $\mathrm{RT}(3,4)$. IOERT is a therapeutic technique which consists of administering a single high dose of ionizing radiation (IR) immediately after surgical removal of tumor to destroy residual cancer cells that may be left at the tumor site. Indeed, this typically represents a site at high risk for recurrence. According to specific eligibility criteria, IOERT may be exclusive with the provision of a single radiation dose of 21-23 Gy corresponding to the administration of the entire sequence of a conventional adjuvant RT, or an anticipated boost of 9-12 Gy, followed by conventional external RT to guarantee for optimal accuracy in dose delivery (4-6).

Technological advances in radiation delivery have increased tumor cell-killing capacity with higher precision by increasing doses and saving organs at risk, with high doses being delivered to tumor targets, even of a small size. However, considering that high tumor heterogeneity, in terms of molecular and clinical characteristics of BC, may affect the RT outcome, the choice of an RT plan common to all patients may not be the best option. Indeed, the total dose and number of fractions administered during RT schedules do not take into account molecular differences that affect radiosensitivity and response variability of different tumor subtypes $(6,7)$. Thus, many efforts in radiobiological research are needed to help clinicians in understanding molecular features of specific tumor subtypes in order to better define the most successful treatment plan, including the choice of the best RT modality and schedule in clinical 
practice $(7,8)$. Therefore, considering that the response to RT is highly variable, cell type-dependent and dosedependent, it is necessary to estimate the biological effects of IR using an '-omics' approach, which would allow identification of molecular-based signatures as biomarkers of tumor and normal cell radiation response (9-12). Indeed, the use of gene-expression profiling (GEP) after radiation exposure is fundamental to the development of a number of signatures, either predictive or prognostic for outcomes of patients with $\mathrm{BC}(7,13)$. These signatures vary widely for their specificity in BC outcomes and RT success plans, underlining their relationship with specific BC subtypes (13).

The aim of this study was to analyze GEP in primary BC cells following irradiation with doses of 9 Gy and 23 Gy electron beam delivered by boost and exclusive IOERT, respectively, in order to define gene signatures of response to high doses of IR. Primary cells are more representative of the tissue from which they are derived as compared to the immortalized cell lines and represent a powerful system for studying cell behavior and cellular pathways, particularly after treatment (14-15).

\section{Materials and Methods}

Radiation treatments. The NOVAC7 IOERT system (Sortina IOERT Technologies, Vicenza, Italy) producing electron beams of 4, 6, 8 and $10 \mathrm{MeV}$ nominal energies was used to perform treatment plans. Beam collimation was performed through a set of polymethyl methacrylate applicators. IOERT cell treatments were conducted at two doses, 9 Gy in boost scheme, and $23 \mathrm{~Gy}$ according to the exclusive modality, to the $100 \%$ isodose at a dose rate of 3.2 cGy/pulse. Cell irradiation setup and the dose distribution were conducted as previously reported $(9,10)$.

Cell culture and evaluation of cell survival. Human mammary primary cells were isolated by our group from breast surgery specimens of infiltrating ductal carcinoma and cultured as previously described (14). The study and the consent procedure were performed according to the Helsinki declaration and were approved by the Ethical Committee of Hospital San Raffaele G. Giglio hospital, Cefalù-Italy (number of protocol: C.E.2012/16). The two primary BC cultures used for this study, were named and classified according to their estrogen (ER), progesterone (PR) and ERBB2 receptor tyrosine kinase 2 (HER2) receptor status (negative or positive), as follows: BCpcEMT (ER-/PR-/HER2-), which displayed a strong signature for the epithelial-mesenchymal transition (EMT), and BCpc7 (ER+/PR+/HER2-) (14). In addition, we used normal human mammary epithelial cells (HMEC), as a reference sample comparing it with the two primary $\mathrm{BC}$ cell lines investigated in this work. HMECs were purchased from Invitrogen (Carlsbad, CA, USA) and cultured according to the supplier's instructions. Media and supplements were also obtained from Invitrogen. All cell cultures were maintained at $37^{\circ} \mathrm{C}$ in an incubator with $5 \% \mathrm{CO}_{2}$. Cells were seeded in $100-\mathrm{mm}$ petri dishes 48 hours before treatments and were irradiated at subconfluence.

To evaluate cell survival, cells were counted with a Countess Automated Cell Counter and Burker camera according the manufacturer's instructions (Invitrogen, Carlsbad, CA, USA). Twenty four hours after irradiation, cells were seeded at a density of $50-100 \times 10^{3}$ cells per well in $60-\mathrm{mm}$ petri dishes. Cells were maintained in culture for 1 week and the medium was replaced every 3 days. As a control (basal), untreated cells were seeded and grown under the same conditions. Seven days after seeding, cells were counted and the percentage of cell survival was obtained with respect to the cell number of untreated sample.

The data shown were generated from three independent experiments and the values of cell survival are expressed as the mean \pm SD.

During incubation, cells were monitored to analyze cell morphology and growth pattern following RT by photographing several random fields under a phase-contrast microscope (Carl Zeiss, Göttingen, Germany).

Whole-genome cDNA microarray expression analysis. GEP of HMEC, BCpc7 and BCpcEMT primary cell cultures treated with 9 and 23 Gy IR doses were performed. Twenty-four hours after each treatment, cells were harvested, counted and the pellet stored immediately at $-80^{\circ} \mathrm{C}$. Total RNA was extracted from cells and evaluated for its concentration and purity as previously reported (9, 10). Five hundred nanograms of total RNA were used for cRNA synthesis and labeling according to the Agilent Two-Color Microarray-Based Gene Expression Analysis protocol (Agilent Technologies, Santa Clara, CA, USA). Complementary cRNA samples labeled with $\mathrm{Cy} 5$ and $\mathrm{Cy} 3$ dye (Agilent Technologies) were hybridized onto Whole Human Genome 4x44K microarray (Agilent Technologies). GeneChips contained all known genes and transcripts of an entire human genome. Four replicates were performed. Array hybridization, microarray scanning and feature analysis were performed as previously described in detail $(9,10)$. Statistical data analysis, background correction, normalization and summary of expression measures were conducted with GeneSpring GX 10.0.2 software (Agilent Technologies). Finally, statistically significant differences were computed by Student's t-test and the significance level was set at $p<0.05$. The false discovery rate (FDR) was determined as a multiple test correction method. Average gene expression values between experimental groups were compared (on $\log$ scale) by means of a modified ANOVA $(p<0.05)$.

Genes were identified as differentially expressed if they showed a fold-change (FC) of at least 1.5 and a value of $p<0.05$ compared to untreated HMEC, BCpc7 and BCpcEMT cells used as reference samples. In addition, the GEPs obtained in this work were also analyzed by pathway analysis using the Database for Annotation, Visualization and Integrated Discovery (DAVID) network building tool that provides a comprehensive set of functional annotation tools for investigators to understand the biological meaning behind a long list of genes (https://david.ncifcrf.gov/tools.jsp). The most representative significantly changed networks and pathways were selected and analyzed. The data discussed in this publication were deposited in the NCBI Gene Expression Omnibus (16) and are accessible through GEO Series accession number (GSE110933). Microarray data are available in compliance with Minimum Information About a Microarray Experiment standards (17).

Real-time quantitative reverse transcription polymerase chain reaction (qRT-polymerase chain reaction). Candidate genes for $\mathrm{qRT}$ PCR analysis were chosen based on the microarray results. Total RNA was reverse-transcribed into cDNA with SuperScript II reverse transcriptase according to the manufacturer's specifications and then analyzed by real-time PCR in triplicate using a Fast 7500 Real-Time 
PCR System (Applied Biosystems, Carlsbad, CA, USA), as previously described $(9,10)$. Reaction specificity was controlled by post-amplification melting-curve analysis. The oligonucleotide primers chosen for qRT-PCR were selected with Primer3 software $(18,19)$, tested for their human specificity using the NCBI database and are available on request. Quantitative data, normalized versus that for the rRNA $18 S$ gene, were analyzed by the average of triplicate cycle threshold (Ct) according to the $2^{-\Delta \Delta \mathrm{ct}}$ method using SDS software (Applied Biosystems). The data shown were generated from three independent experiments and the values are expressed as the mean $\pm \mathrm{SD}$ relative to mRNA levels in the untreated HMEC, BCpc7 and BCpcEMT cells used as the control samples.

\section{Results}

Cell survival and morphology. In order to evaluate the survival of primary cells, 24 hours after irradiation exposure to radiation doses of $9 \mathrm{~Gy}$ and $23 \mathrm{~Gy}$, cells were counted, seeded and maintained in culture for 1 week. After this time, cells in each irradiated sample were counted and the percentage of cell survival was obtained relative to the cell number of the untreated sample. We observed a significantly high survival rate in the both primary BC cell cultures following high-dose radiation treatments. In particular, cell survival of the BCpcEMT cells was more than twice that of BCpc7 cells at 9 Gy and $23 \mathrm{~Gy}$, respectively. Cell survival of the normal HMECs was lower than that of tumor cells, practically half, at 23 Gy (Figure1A).

During the incubation, cells were monitored for cell morphology by photographing some random fields under a phase-contrast microscope in order to evaluate growth pattern following RT. In the case of HMECs, morphological alterations were observed following both treatments, further highlighting the low survival rate of normal mammary cells at high doses (Figure 1B). In the case of both types of primary BC cells, which were more resistant to treatments than normal cells, no consistent radiation-induced morphological changes were observed. In particular, after treatments of 9 and $23 \mathrm{~Gy}$, the BCpcEMT cells maintained unchanged their phenotypic characteristics of EMT, previously described by our group (14), such as stellate morphology, cytoplasmic protrusions, and multilayered growth in the absence of contact inhibition (Figure 1B). Finally, the BCpc7 cells maintained their epithelial characteristics unchanged (Figure 1B).

Overview of cDNA microarray gene expression. In this study, whole human genome Microarray-Based Gene Expression Analyses (Agilent Technologies) were conducted on cultures of two BC cell lines (BCpc7 and BCpcEMT) and one of normal cells (HMEC) exposed to irradiation of $9 \mathrm{~Gy}$ and 23 Gy. The corresponding samples of untreated cells, i.e. HMEC, BCpc7 and BCpcEMT were used as reference samples. Comparative differential gene-expression analysis revealed that expression of a conspicuous number of genes was significantly altered by 1.5 -fold or greater compared to the untreated reference group. Venn diagrams shown in Figure 2 display the number of unique and shared differentially expressed genes of the cells exposed to IR doses of 9 and 23 Gy analyzed in this work. Up- and down-regulated transcripts belonging to all the gene lists were selected and grouped according to their involvement in specific biological pathways using integrated pathway enrichment analysis with DAVID and REACTOME tool (https://david.ncifcrf.gov/tools.jsp; https://reactome.org). The result of this mapping revealed the involvement of a set of factors controlling specific networks, principally involved in cell cycle and inflammation modulation processes. In addition, gene lists were also analyzed using PubMatrix tool as previously described (9-10). In this way, candidate genes were selected and used to validate microarray datasets by qRT-PCR analyses that confirm gene-expression trends (Table I). Moreover, we used HMECs as a reference normal sample and validated the following differentially expressed genes between HMEC treated at 9 Gy and 23 Gy: Breast cancer 2 (BRCA2); BRCA2 and cyclin-dependent kinase inhibitor-interacting protein $(B C C I P)$; cyclin-dependent kinase inhibitor $3(C D K N 3)$; E2F transcription factor 2 (E2F2); Homo sapiens kinesin family member 20A (KIF20A); NUF2; NDC80 kinetochore complex component (NUF2); small nuclear ribonucleioprotein polypeptide $\mathrm{N}$ upstream reading frame $(S N U R F)$; tumor necrosis factor receptor superfamily,member 10c (TNFRSF10C); budding uninhibited by benzimidazoles 1 (BUB1); cell-division cycle 20 (CDC20) cell-division cycle 25 homolog C; centromere protein F, 350/400kDa (CENPF); and never in mitosis gene A-related kinase 2 (NEK2). These genes are mainly involved in controlling the cell cycle, DNA repair and chromosomal stability, and the results were in line with those previously obtained by our group in the non-tumorigenic mammary MCF10A cell line treated with the same doses and used as a control (10).

Analysis of radiation gene signatures. We compared the list of deregulated genes of primary BC cells treated with the same dose (9 Gy or $23 \mathrm{~Gy}$ ), producing Venn diagrams as displayed in Figure 3. Four deregulated genes were found to be common to BCpc7 and BCpcEMT BC cells exposed to 9 Gy. Six deregulated genes were shared between the two primary $\mathrm{BC}$ cell cultures exposed to $23 \mathrm{~Gy}$. These two gene signatures were validated by qRT-PCR assays, confirming their gene-expression trend and their roles in driving cell response induced by high dose of IR delivered during radiotherapy (Table I). In detail, the 4-gene signature of primary BC cells exposed to 9 Gy comprised the following genes: Amphiregulin (AREG), FBJ murine osteosarcoma viral oncogene homolog $(F O S)$, FBJ murine osteosarcoma viral oncogene homolog B (FOSB) and Ras-related associated with diabetes (RRAD) (Figure 3A). The 6-gene signature for primary $\mathrm{BC}$ cells exposed to $23 \mathrm{~Gy}$ is displayed in Figure $3 \mathrm{~B}$ and comprised AREG; FOS; FOSB; growth differentiation 

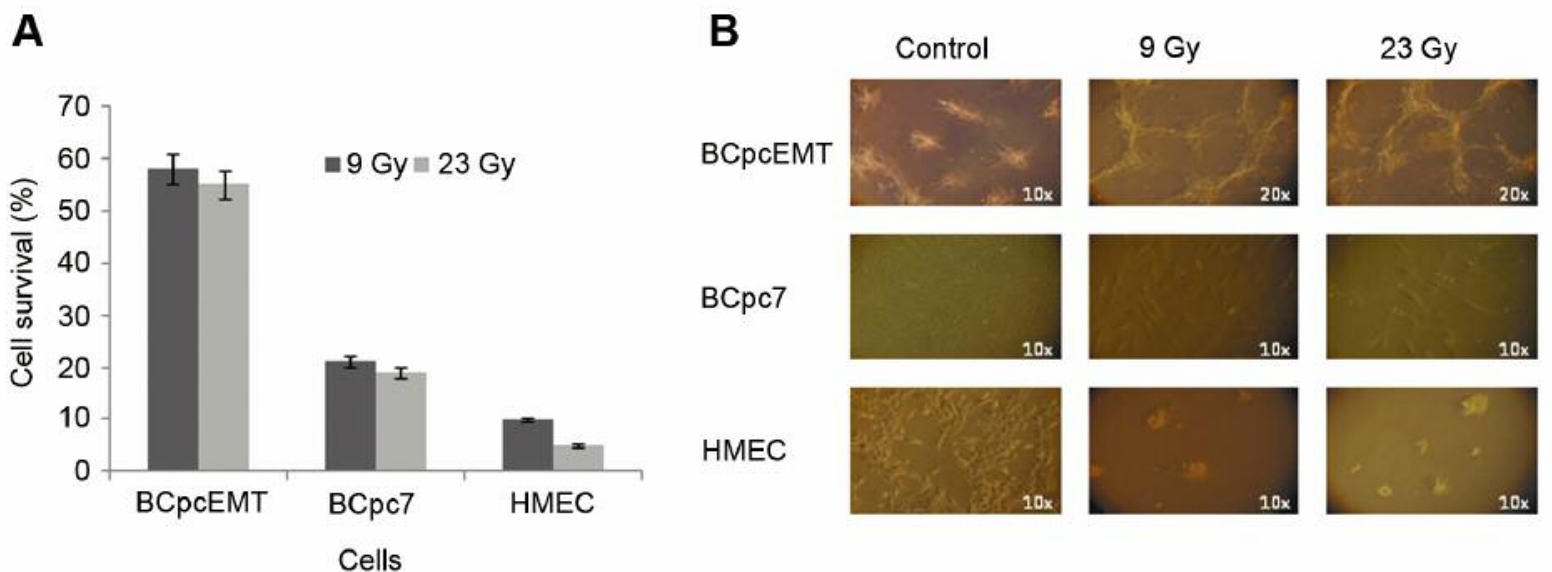

BCpc7
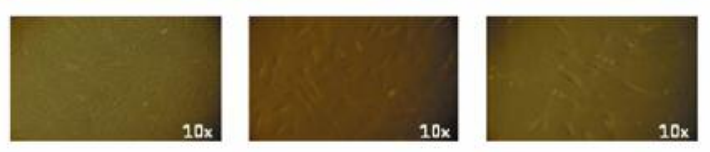

HMEC
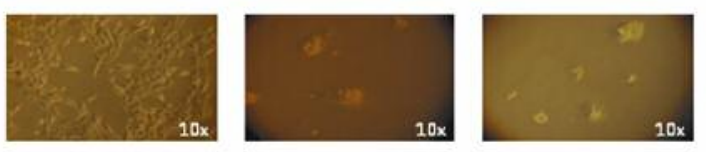

Figure 1. A: Percentage of cell survival after 8 days post-treatment with 9 and 23 Gy of doses in cultures of primary breast cancer BCpc7, BCpcEMT (with strong signature for the epithelial-mesenchymal transition), and normal human mammary epithelial cells (HMEC), with respect to the cell number of each untreated basal sample (control). B: Micrographs of cells 8 days after radiotherapy to evaluate morphological growth pattern.

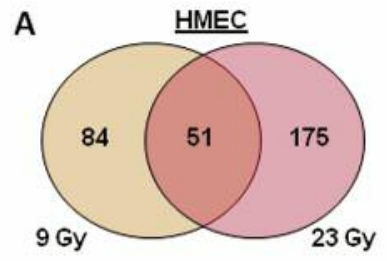

\begin{tabular}{c|c|c|c} 
& DEG $^{\circ}$ & Down & Up \\
\hline 9 Gy & 135 & 77 & 58 \\
\hline 23 Gy & 226 & 133 & 93
\end{tabular}

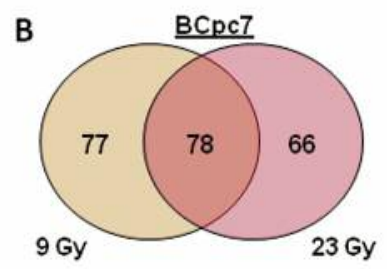

\begin{tabular}{c|c|c|c} 
& DEG $^{\circ}$ & Down & Up \\
\hline 9 Gy & 155 & 105 & 50 \\
\hline 23 Gy & 144 & 46 & 98
\end{tabular}

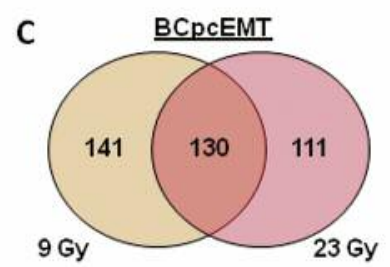

\begin{tabular}{c|c|c|c} 
& DEG $^{\circ}$ & Down & Up \\
\hline $9 G y$ & 271 & 202 & 69 \\
\hline $23 G y$ & 241 & 66 & 175
\end{tabular}

Figure 2. Venn diagrams showing the number of unique and shared differentially expressed genes (DEG) after exposure to doses of 9 and 23 Gy of cultures of primary breast cancer BCpc7, BCpcEMT (with strong signature for the epithelial-mesenchymal transition), and normal human mammary epithelial cells (HMEC), analyzed in this work. Genes whose expression was significantly altered by 1.5-fold or greater after irradiation compared to the untreated reference group were included.

factor 15 (GDF15); glutamate ionotropic receptor $N$-methylD-aspartate (NMDA) type subunit 2C (GRIN2C); TAF7-like RNA polymerase II TATA box binding protein-associated factor, $50 \mathrm{kDa}(T A F 7 L)$. The genes belonging to these gene signatures were then analyzed using the PubMatrix tool (19). In this way, lists of terms, such as gene names, were assigned to a genetic, biological, or clinical relevance in a flexible systematic fashion in order to confirm our assumptions. 
A
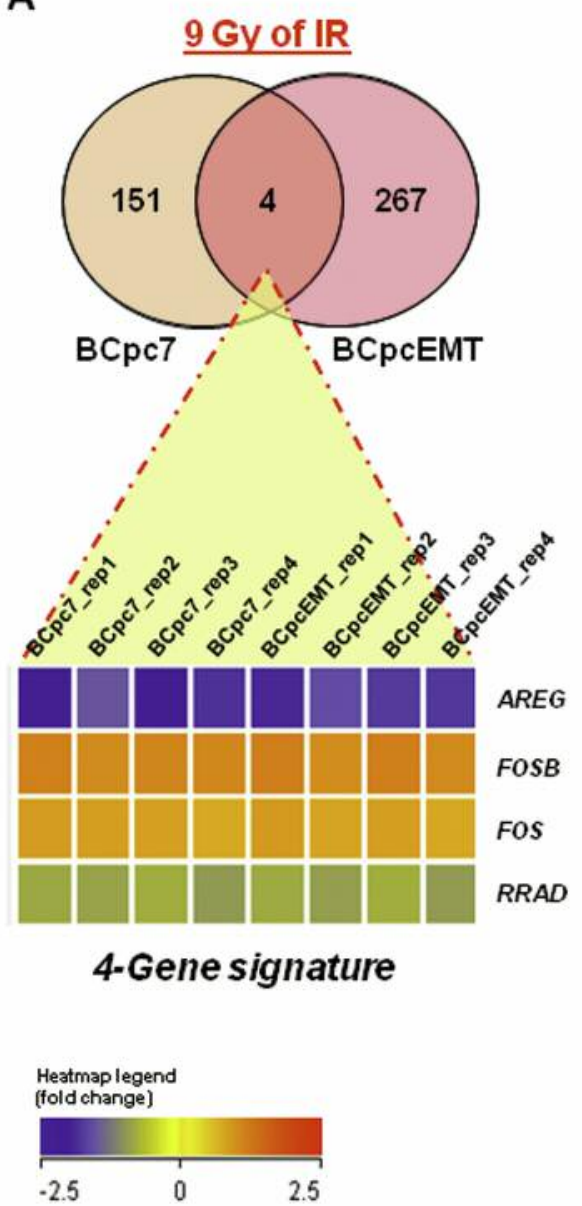

B

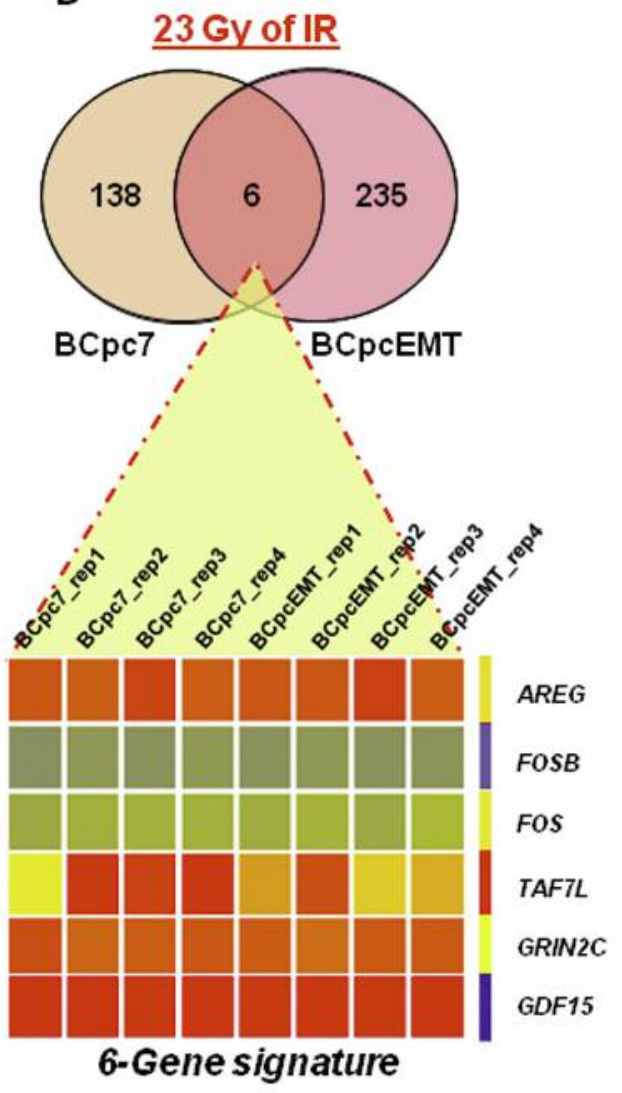

Figure 3. Heatmaps of the 4- and 6-gene signatures selected in primary breast cancer BCpc7, BCpcEMT (with strong signature for the epithelialmesenchymal transition), and normal human mammary epithelial cells (HMEC) exposed to ionizing radiation (IR) doses of 9 Gy and 23 Gy.

Bibliographic relationships between proteins and selected queries such as IR, radiation, cancer, BC, inflammation, and apoptosis were analyzed in order to understand the data and to draw useful conclusions reported below.

\section{Discussion}

The aim of the study was to analyze the GEPs in primary BC cell cultures following irradiation with IR at high doses in order to define gene-expression signatures related to the response of tumor and normal cells to radiotherapy. Today, to our knowledge no radiobiological studies have been conducted on primary BC cells isolated from surgically removed breast tumors. Primary cells are more representative of the tissue from which they are derived compared to immortalized cell lines and therefore represent a powerful system for studying cell behavior and cellular pathways, particularly after treatment $(14,15)$.
Firstly, we evaluated cell survival of primary cells exposed to 9 and 23 Gy doses according to boost and exclusive IOERT, respectively, used for treatment of some patients with $\mathrm{BC}$ (4-6). After 8 days from irradiation at both doses, primary BC cells had a significantly high survival rate. Tumor cell survival ranged from $19-58 \%$, while the cell survival of the normal cells was lower, at $5 \%$ and $10 \%$.

In addition, we noted some differences in morphological traits following high-dose irradiation of breast cells. In the case of the normal cells, morphological alterations after both doses were observed. On the contrary, both primary BC cell cultures, which were more resistant to irradiation than normal cells, showed no consistent radiation-induced morphological alterations. BCpcEMT cells appeared to maintain fully their malignant EMT phenotypic traits, previously described by our group $(14,15)$.

The utilization of gene-expression changes induced by radiation exposure as a molecular signature may have 
Table I. Genes validated as being deregulated in primary breast cancer BCpc7, BCpcEMT (with strong signature for the epithelial-mesenchymal transition), and normal human mammary epithelial (HMEC) cells treated with 9 Gy and 23 Gy as determined by quantitative reverse transcriptionpolymerase chain reaction ( $q R T-P C R)$. Gene-expression data are reported as fold change that of untreated cells used as reference sample.

\begin{tabular}{|c|c|c|c|c|c|c|c|c|c|c|c|c|c|}
\hline \multirow[b]{3}{*}{$\begin{array}{l}\text { Gene } \\
\text { symbol }\end{array}$} & \multirow[b]{3}{*}{ Full name } & \multicolumn{4}{|c|}{ HMEC } & \multicolumn{4}{|c|}{ BCpc7 } & \multicolumn{4}{|c|}{ ВСрсЕМТ } \\
\hline & & \multicolumn{2}{|c|}{9 Gy } & \multicolumn{2}{|c|}{$23 \mathrm{~Gy}$} & \multicolumn{2}{|c|}{9 Gy } & \multicolumn{2}{|c|}{$23 \mathrm{~Gy}$} & \multicolumn{2}{|c|}{9 Gy } & \multicolumn{2}{|c|}{$23 \mathrm{~Gy}$} \\
\hline & & Array & $\begin{array}{l}\text { qRT- } \\
\text { PCR }\end{array}$ & Array & $\begin{array}{l}\text { qRT- } \\
\text { PCR }\end{array}$ & Array & $\begin{array}{l}\text { qRT- } \\
\text { PCR }\end{array}$ & Array & $\begin{array}{l}\text { qRT- } \\
\text { PCR }\end{array}$ & Array & $\begin{array}{l}\text { qRT- } \\
\text { PCR }\end{array}$ & Array & $\begin{array}{l}\text { qRT- } \\
\text { PCR }\end{array}$ \\
\hline ACTA2 & Alpha 2, smooth muscle, aorta & - & - & - & - & - & - & - & - & 1.24 & 1.17 & -1.24 & 0.40 \\
\hline ANO2 & Anoctamin 2 & - & - & - & - & - & - & - & - & - & - & 1.58 & 10.27 \\
\hline$A R E G$ & Amphiregulin & - & - & - & - & -7.17 & 0.96 & 2.09 & 2.51 & -2.82 & 0.64 & 2.62 & 2.53 \\
\hline AXIN2 & Axin 2 & - & - & - & - & - & - & - & - & -1.50 & 0.65 & 1.85 & 7.30 \\
\hline$B C C I P$ & $\begin{array}{l}\mathrm{BRCA} 2 \text { and } \mathrm{CDKN} 1 \mathrm{~A} \\
\text { interacting protein }\end{array}$ & - & - & -1.15 & 0.74 & - & - & - & - & - & - & - & - \\
\hline$B R C A 2$ & Breast cancer 2 & - & - & -1.40 & 0.31 & - & - & - & - & - & - & - & - \\
\hline$B U B 1$ & $\begin{array}{l}\text { Budding uninhibited by } \\
\text { benzimidazoles } 1\end{array}$ & 1.51 & 1.84 & - & - & - & - & - & - & - & - & - & - \\
\hline$C A V 1$ & Caveolin 1 & - & - & - & - & -1.11 & 0.44 & - & - & 1.02 & 1.29 & -1.04 & 0.78 \\
\hline$C D 55$ & CD55 molecule & - & - & - & - & - & - & 6.97 & 8.7 & -2.40 & 0.68 & 3.13 & 21.40 \\
\hline$C D C 20$ & Cell division cycle 20 & 1.48 & 1.1 & -1.62 & 0.86 & - & - & - & - & - & - & - & - \\
\hline$C D C 25 C$ & $\begin{array}{l}\text { Cell division cycle } 25 \\
\text { homolog } \mathrm{C}\end{array}$ & 1.51 & 1.16 & - & - & - & - & - & - & - & - & - & - \\
\hline$C D K N 1 A / p 21$ & $\begin{array}{l}\text { Cyclin-dependent kinase } \\
\text { inhibitor 1A (p21, Cip1) }\end{array}$ & - & - & & - & - & - & - & - & - & - & 1.35 & 5.40 \\
\hline$C D K N 3$ & Cyclin-dependent kinase inhibitor 3 & - & - & -1.49 & 0.19 & - & - & - & - & - & - & - & - \\
\hline CENPF & $\begin{array}{l}\text { Centromere protein F, } \\
\text { 350/400kDa (mitosin) }\end{array}$ & 1.28 & 1.97 & - & - & - & - & - & - & - & - & - & - \\
\hline CLDN1 & Claudin 1 & - & - & - & - & - & - & - & - & - & - & 3.68 & 7.70 \\
\hline$E 2 F 2$ & E2F transcription factor 2 & - & - & -1.19 & 0.9 & - & - & - & - & - & - & - & - \\
\hline$E G R 2$ & Early growth response 2 & - & - & - & - & - & - & 1.14 & 4.2 & - & - & 2.19 & 26.70 \\
\hline EPHA4 & EPH receptor A4 & - & - & - & - & - & - & 1.87 & 2.5 & - & - & 1.71 & 7.70 \\
\hline FOS & $\begin{array}{l}\text { FBJ murine osteosarcoma } \\
\text { viral oncogene homolog }\end{array}$ & - & - & - & - & 3.35 & 5.5 & -1.12 & 0.4 & 1.57 & 1.2 & -1.57 & 0.07 \\
\hline$F O S B$ & $\begin{array}{l}\text { FBJ murine osteosarcoma } \\
\text { viral oncogene homolog B }\end{array}$ & - & - & - & - & 3.31 & 6.98 & -1.54 & 0.60 & 1.8 & 1.9 & -1.78 & 0.28 \\
\hline$F Y B$ & FYN binding protein & - & - & - & - & - & - & - & - & 1.57 & 9.6 & - & - \\
\hline GADD45 & $\begin{array}{l}\text { Growth arrest and DNA- } \\
\text { damage-inducible }\end{array}$ & - & - & - & - & -1.21 & 0.4 & - & - & -1.56 & 0.48 & - & - \\
\hline GDF15 & Growth differentiation factor 15 & - & - & - & - & - & - & 1.32 & 95 & - & - & 3.75 & 21.20 \\
\hline GDNF & Glial cell derived neurotrophic factor & $r-$ & - & - & - & - & - & - & - & - & - & 1.62 & 3.70 \\
\hline GRIN2C & $\begin{array}{l}\text { Glutamate ionotropic receptor } \\
\text { NMDA type subunit } 2 \mathrm{C}\end{array}$ & & & & & - & - & 1.81 & 3.8 & - & - & 2.43 & 7.80 \\
\hline HIST1H1 & Homo sapiens histone cluster $1, \mathrm{H} 1 \mathrm{a}$ & - & - & -1.53 & 0.89 & - & - & - & - & - & - & - & - \\
\hline HISTIH3F & Homo sapiens histone cluster $1, \mathrm{H} 3 \mathrm{f}$ & - & - & - & - & -1.48 & 0.03 & -3.31 & 0.049 & -1.12 & 0.23 & - & - \\
\hline$J U N$ & Homo sapiens jun proto-oncogene & - & - & - & - & 1.07 & 1.4 & 1.16 & 1.97 & 1.12 & 1.4 & -1.12 & 0.40 \\
\hline$J U N B$ & Homo sapiens jun B proto-oncogene & - & - & - & - & 1.17 & 1.78 & 1.55 & 1.24 & 1.14 & 1.15 & -1.18 & 0.28 \\
\hline KIF20A & $\begin{array}{l}\text { Homo sapiens kinesin family } \\
\text { member } 20 \mathrm{~A}\end{array}$ & - & - & -1.53 & 0.1 & - & - & - & - & - & - & - & - \\
\hline$L A M P 3$ & $\begin{array}{l}\text { Lysosomal-associated } \\
\text { membrane protein } 3\end{array}$ & - & - & - & - & - & - & - & - & - & - & 3.25 & 24.00 \\
\hline$M D M 2$ & Mdm2 p53 binding protein homolog & - & - & - & - & - & - & 1.16 & 13.4 & - & - & 1.43 & 17.30 \\
\hline$N E K 2$ & $\begin{array}{l}\text { Never in mitosis gene } \\
\text { A-related kinase } 2\end{array}$ & 1.62 & 1.3 & -1.59 & 0.37 & - & - & - & - & - & - & - & - \\
\hline$N F K B 1$ & $\begin{array}{l}\text { Nuclear factor of kappa light } \\
\text { polypeptide gene enhancer } \\
\text { in B-cells } 1\end{array}$ & - & - & - & - & - & - & - & - & - & - & -1.05 & 0.82 \\
\hline$N R 4 A 2$ & $\begin{array}{l}\text { Nuclear receptor subfamily } \\
4 \text {, group A, member } 2\end{array}$ & - & - & - & - & 2.76 & 1.77 & - & - & - & - & - & - \\
\hline NTN1 & Netrin 1 & - & - & - & - & - & - & 1.82 & 32.2 & - & - & - & - \\
\hline
\end{tabular}




\begin{tabular}{|c|c|c|c|c|c|c|c|c|c|c|c|c|c|}
\hline \multirow[b]{3}{*}{$\begin{array}{l}\text { Gene } \\
\text { symbol }\end{array}$} & \multirow[b]{3}{*}{ Full name } & \multicolumn{4}{|c|}{ HMEC } & \multicolumn{4}{|c|}{ BCpc7 } & \multicolumn{4}{|c|}{ ВСрсЕМТ } \\
\hline & & \multicolumn{2}{|c|}{9 Gy } & \multicolumn{2}{|c|}{$23 \mathrm{~Gy}$} & \multicolumn{2}{|c|}{9 Gy } & \multicolumn{2}{|c|}{$23 \mathrm{~Gy}$} & \multicolumn{2}{|c|}{9 Gy } & \multicolumn{2}{|c|}{$23 \mathrm{~Gy}$} \\
\hline & & Array & $\begin{array}{l}\text { qRT- } \\
\text { PCR }\end{array}$ & Array & $\begin{array}{l}\text { qRT- } \\
\text { PCR }\end{array}$ & Array & $\begin{array}{l}\text { qRT- } \\
\text { PCR }\end{array}$ & Array & $\begin{array}{l}\text { qRT- } \\
\text { PCR }\end{array}$ & Array & $\begin{array}{l}\text { qRT- } \\
\text { PCR }\end{array}$ & Array & $\begin{array}{l}\text { qRT- } \\
\text { PCR }\end{array}$ \\
\hline$N U F 2$ & $\begin{array}{l}\text { NUF2, NDC80 kinetochore } \\
\text { complex component }\end{array}$ & - & - & -1.65 & 0.1 & - & - & - & - & - & - & - & - \\
\hline$O C L N$ & Occludin & - & - & - & - & - & - & 1.52 & 3.7 & - & - & - & - \\
\hline PLAC2 & Placenta-specific 2 & - & - & - & - & - & - & - & - & -1.83 & 0.57 & 1.64 & 6.82 \\
\hline PLK1 & Polo-like kinase 1 & - & - & - & - & - & - & - & - & - & - & -1.26 & 0.02 \\
\hline$R R A D$ & Ras-related associated with diabetes & & & & & -1.61 & 0.42 & - & - & -1.65 & 0.71 & 1.68 & 2.00 \\
\hline SNURF & SNRPN upstream reading frame & -2.10 & 0.6 & -1.46 & 0.56 & - & - & - & - & - & - & - & - \\
\hline$S U L F 2$ & Sulfatase 2 & - & - & - & - & - & - & 1.20 & 6.2 & - & - & 1.91 & 8.60 \\
\hline$T A F 7 L$ & $\begin{array}{l}\text { TAF7-like RNA polymerase II, } \\
\text { TATA box binding protein }\end{array}$ & - & - & - & - & -1.72 & 0.91 & 1.53 & 4.97 & - & - & 2.11 & 10.00 \\
\hline TNFRSF10C & $\begin{array}{l}\text { Necrosis factor receptor } \\
\text { superfamily, member } 10 \mathrm{c}\end{array}$ & -1.67 & 0.6 & -1.72 & 0.83 & - & - & - & - & - & - & - & - \\
\hline TOP $2 A$ & $\begin{array}{l}\text { Topoisomerase (DNA) II } \\
\text { alpha } 170 \mathrm{kDa}\end{array}$ & - & - & -1.60 & 0.19 & - & - & - & - & - & - & - & - \\
\hline TP53 & Tumor protein p53 & - & - & - & - & -1.10 & 0.78 & 1.15 & 1 & - & - & - & - \\
\hline TP53INP1 & $\begin{array}{l}\text { Tumor protein p53 inducible } \\
\text { nuclear protein } 1\end{array}$ & - & - & - & - & - & - & 1.63 & 3.18 & - & - & 1.51 & 2.84 \\
\hline TSGA10 & Testis specific, 10 & - & - & - & - & - & - & - & - & - & - & 1.88 & 9.59 \\
\hline$V I M$ & Vimentin & - & - & - & - & 1.11 & 0.91 & -1.11 & 0.51 & - & - & -1.05 & 0.40 \\
\hline
\end{tabular}

predictive or prognostic significance for outcomes of $\mathrm{BC}$ (13). These molecular signatures differ in specific BC subtypes, thus highlighting their specificity for BC outcomes and successful RT plans. In this work, we selected two specific dose-related gene signatures (Figure 3) common to the two primary $\mathrm{BC}$ cell cultures.

Among the genes of the 4-gene signature, FOS and FOSB were selected underlining once again, their driving key role in cell response after radiation exposure, described by several authors and also by our group (9-11). The exposure of mammalian cells to extracellular stress, such as IR, induces the expression of immediate early genes, comprising FOS factors, involved in stabilization of heterodimeric activator protein 1 (AP1) transcription factor. Thus, AP1 is often described as playing an important role in the induction and development of late radiation effects $(21,22)$. As reported in Figure 3A, FOS and FOSB were up-regulated after 9 Gy, data in line with those recently published by our group for the MCF7 BC cell line exposed to high-dose IR (9). FOSB in mammary epithelial cells has been shown to regulate cell proliferation, differentiation and death, and in BC cells, it is also able to increase the expression of matrix metallopeptidase 9 (MMP9), regulating apoptotic processes. Jun protooncogene $(J U N)$ and FOS family members are known to be able to interact and form multiple AP1 dimers, which differ not only in their efficacy of binding to DNA, but also in stability of binding and transcriptional activation of target genes, depending on the type and radiation dose (22). In this sense, FOS and FOSB are described as strong transactivators of AP1 complex formation and their expression seems to be related to high-dose IR used during IOERT irradiation (23).

The other two differentially expressed genes common to 9 Gy-treated BCpc7 and BCpcEMT cells, and included in the 4gene signature, were $A R E G$ and $R R A D$. Interestingly $A R E G$ gene, a ligand of the epidermal growth factor receptor (EGFR), plays a central role in mammary gland development and is expressed both in healthy and in cancerous tissues (24). The oncogenic activity of AREG has already been described in the most common human epithelial malignancies including of the breast and was also described as a prognostic or predictive cancer marker, especially with regard to anti-EGFR therapies (25). In addition, as reported by Higginbotham et al., AREG is secreted in exosomes and increases cell invasion and metastasis in various cancer types, including BC (26). In turn, this new biomarker is involved in resistance to several cancer treatments and is now under evaluation for specific targeted therapeutic interventions (24). Very few data are available regarding the role of AREG after radiation exposure, which in our opinion needs to be explored.

Finally, limited but encouraging data on the role of small Ras related GTPase RRAD in cancer cell development was recently described. RRAD has been implicated in metabolic 
disease and in several types of cancer. Its expression is frequently down-regulated in cancer (a trend also observed in this work), and it is able to repress the Warburg effect associated with tumor progression and poor prognosis (27). Moreover, Shang et al. described this factor as being able to predict poor clinical outcome of patients with hepatocellular carcinoma, playing an important role in regulating aerobic glycolysis, cell invasion and metastasis, thereby representing a potential target for improving cancer treatment (27). To our knowledge, no data regarding the role of RRAD in radiation cell response has been reported. In this sense, in our opinion this factor needs further studies, considering that it is also a newly identified p53 target and thus it could have a role in different processes regulating cell fate decision (27-29).

On the other hand, a 6-gene signature was selected for primary $\mathrm{BC}$ cells exposed to the high dose of $23 \mathrm{~Gy}$ (Figure 3B). This signature includes AREG, FOS and FOSB genes already described above. In addition, GDF15, GRIN2C and $T A F 7 L$ genes were differentially expressed compared to untreated cells. GDF15, which was overexpressed after irradiation in both primary $\mathrm{BC}$ cell cultures, encodes a secreted ligand of the transforming growth factor-beta superfamily of proteins and belongs to the growth differentiation factor family, able to regulate gene expression. The protein acts as a pleiotropic cytokine and is involved in the cell stress response program after cellular injury such as radiation exposure, hypoxia, inflammation, and acute injury oxidative stress (30-32). Interestingly, GDF15 was recently described as a potential marker of radiation response and sensitivity. Its expression was found to be time- and dosedependent, suggesting that GDF15 might represent a radiationinduced biomarker. Moreover, it is a p53 target gene which can modulate the transcription of other p53 targets and is also able to regulate cell death/survival balance, underlying its relevance in cell radiation response (30-32).

On the other hand, very few data have been reported for $T A F 7 L$ which was up-regulated in BCpc7 and in BCpcEMT cells treated with an IR dose of $23 \mathrm{~Gy}$. This gene encodes for a TATA box binding protein-associated factor, shows testis-specific expression and was recently described as being up-regulated in $\mathrm{BC}$ and other tumors (33).

Finally, the GRIN2C gene, which encodes for a subunit of the NMDA receptor (34) was also included in the selected 6-gene signature, because it was differentially up-regulated after radiation exposure in both primary $\mathrm{BC}$ cell cultures with respect to untreated cells. However, no data regarding its role in $\mathrm{BC}$ development or cell response to IR were reported. Consequently, further studies are needed to fill this gap, and in particular as suggested by our GEP data, the role of GRIN2C after cell exposure to a high radiation dose needs to be investigated.

Overall, the two gene signatures selected in this study were formed by genes encoding for factors known to be modulated by IR and also by lesser-known ones involved in cell response to high radiation doses which we propose as new molecular markers.

\section{Conclusion}

In this study, we described, for the first time to our knowledge, the gene- expression signatures induced by high- dose irradiation in primary BC cell cultures in which we observed significantly high survival rates post IOERT treatments. In line with our previous studies and also with other literature data, we reported that the response to radiation is cell-line dependent and that some specific genes and pathway signatures seem to be linked to the dose delivered $(9-10,35-36)$. We present as new molecular markers some common genes of primary BC cells whose expression level changed according to the dose delivered, i.e. a 4-gene signature and a 6-gene signature after exposure at 9 Gy and $23 \mathrm{~Gy}$, respectively. Such signatures of genes activated by different doses of IR may predict response to radiation treatment and contribute to defining a personalized biologically driven treatment plan.

\section{Conflicts of Interest}

The Authors declare that they have no competing interests in regard to this study.

\section{Acknowledgements}

This work was supported by FIRB/MERIT project (RBNE089KHH) and GeSeTON project (funded by Italian MISE grant n. 489 of 21/02/2018).

\section{References}

1 Polyak K: Breast cancer: origins and evolution. J Clin Invest 117: 3155-3163, 2007.

2 Voduc KD, Cheang MC, Tyldesley S, Gelmon K, Nielsen TO and Kennecke H: Breast cancer subtypes and the risk of local and regional relapse. J Clin Oncol 28: 1684-1691, 2010.

3 Yarnold J: Changes in radiotherapy fractionation-breast cancer. Br J Radiol 91: 20170849, 2018.

4 Harris EER and Small W Jr.: Intraoperative radiotherapy for breast cancer. Front Oncol 7: 317, 2017.

5 Sedlmayer F, Reitsamer R, Wenz F, Sperk E, Fussl C, Kaiser J, Ziegler I, Zehentmayr F, Deutschmann H, Kopp P and Fastner G: Intraoperative radiotherapy (IORT) as boost in breast cancer. Radiat Oncol 12(1): 23, 2017.

6 Veronesi U, Orecchia R, Luini A, Galimberti V, Zurrida S, Intra M, Veronesi P, Arnone P, Leonardi MC, Ciocca M, Lazzari R, Caldarella P, Rotmensz N, Sangalli C, Sances D and Maisonneuve P: Intraoperative radiotherapy during breastconserving surgery: a study on 1,822 cases treated with electrons. Breast Cancer Res Treat 124: 141-151, 2010.

7 Lal S, McCart Reed AE, de Luca XM and Simpson PT: Molecular signatures in breast cancer. Methods 131: 135-146, 2017. 
8 Forte GI, Minafra L, Bravatà V, Cammarata FP, Lamia D, Pisciotta P, Cirrone GAP, Cuttone G, Gilardi MC and Russo G: Radiogenomics: the utility in patient selection. Transl Cancer Res 6(Suppl 5): S852-S874, 2017.

9 Bravatà V, Minafra L, Russo G, Forte GI, Cammarata FP, Ripamonti M, Casarino C, Augello G, Costantini F, Barbieri G, Messa $\mathrm{C}$ and Gilardi MC: High-dose ionizing radiation regulates gene expression changes in the MCF7 breast cancer cell line. Anticancer Res 35(5): 2577-2591, 2015.

10 Minafra L, Bravatà V, Russo G, Forte GI, Cammarata FP, Ripamonti M, Candiano G, Cervello M, Giallongo A, Perconti G, Messa C and Gilardi MC: Gene-expression profiling of MCF10A breast epithelial cells exposed to IOERT: Anticancer Res 35(6): 3223-3234, 2015.

11 Minafra L and Bravatà V: Cell and molecular response to IORT treatment. Transl Cancer Res 3: 32-47, 2014.

12 Pucci M, Bravatà V, Forte GI, Cammarata FP, Messa C, Gilardi MC and Minafra L: Caveolin-1, breast cancer and ionizing radiation. Cancer Genomics Proteomics 12(3): 143-152, 2015.

13 Speers $\mathrm{C}$ and Pierce LJ: Molecular signatures of radiation response in breast cancer: Towards personalized decisionmaking in radiation treatment. Int J Breast Cancer 2017: 4279724, 2017.

14 Minafra L, Norata R, Bravatà V, Viola M, Lupo C, Gelfi C and Messa C: Unmasking epithelial-mesenchymal transition in a breast cancer primary culture: A study report. BMC Res Notes 5: $343,2012$.

15 Minafra L, Bravatà V, Forte GI, Cammarata FP, Gilardi MC and Messa C: Gene expression profiling of epithelial-mesenchymal transition in primary breast cancer cell culture. Anticancer Res 34(5): 2173-2183, 2014.

16 Barrett T, Wilhite SE, Ledoux P, Evangelista C, Kim IF, Tomashevsky M, M, Marshall KA, Phillippy KH, Sherman PM, Holko M, Yefanov A, Lee H, Zhang N, Robertson CL, Serova N, Davis S, Soboleva A. NCBI GEO: archive for functional genomics data sets--update. Nucleic Acids Res 41(Database issue): D991-995, 2013.

17 Brazma A, Hingamp P, Quackenbush J, Sherlock G, Spellman P, Stoeckert C, Aach J, Ansorge W, Ball CA, Causton HC, Gaasterland T, Glenisson P, Holstege FC, Kim IF, Markowitz V, Matese JC, Parkinson H, Robinson A, Sarkans U, SchulzeKremer S, Stewart J, Taylor R, Vilo J and Vingron M: Minimum information about a microarray experiment (MIAME)-toward standards for microarray data. Nat Genet 29(4): 365-371, 2001.

18 Rozen S and Skaletsky HJ: Primer3 on the WWW for general users and for biologist programmers. In: Bioinformatics Methods and Protocols: Methods in Molecular Biology. Krawetz S and Misener S (eds.). Humana Press, Totowa, NJ 365-386, 2000.

19 Primer3 tool. Available from http//fokker.wi.mit.edu/primer3. [Last Accessed 3 April 2018]

20 Becker KG, Hosack DA, Dennis G Jr., Lempicki RA, Bright TJ, Cheadle $\mathrm{C}$ and Engel J: PubMatrix: a tool for multiplex literature mining. BMC Bioinform 4: 61, 2003.

21 Zhou H, Gao J, Lu ZY, Lu L, Dai W and Xu M: Role of cFos/JunD in protecting stress-induced cell death. Cell Prolif 40: 431-444, 2007.

22 Benkoussa M, Brand C, Delmotte MH, Formstecher P and Lefebvre $\mathrm{P}$ : Retinoic acid receptors inhibit AP1 activation by regulating extracellular signal-regulated kinase and CBP recruitment to an AP1-responsive promoter. Mol Cell Biol 22: 4522-4534, 2002.
23 Nishad S and Ghosh A: Gene expression of immediate early genes of AP-1 transcription factor in human peripheral blood mononuclear cells in response to ionizing radiation. Radiat Environ Biophys 55: 431-440, 2016.

24 Busser B, Sancey L, Brambilla E, Coll JL and Hurbin A: The multiple roles of amphiregulin in human cancer. Biochim Biophys Acta 1816(2): 119-131, 2011.

25 Peterson EA, Jenkins EC, Lofgren KA, Chandiramani N, Liu H, Aranda E, Barnett M, and Kenny PA: Amphiregulin is a critical downstream effector of estrogen signaling in ER $\alpha$-positive breast cancer. Cancer Res 75(22): 4830-4838, 2015.

26 Higginbotham JN, Demory Beckler M, Gephart JD, Franklin JL, Bogatcheva G, Kremers GJ, Piston DW, Ayers GD, McConnell RE, Tyska MJ and Coffey RJ. Amphiregulin exosomes increase cancer cell invasion. Curr Biol 21(9): 779-786, 2011.

27 Liu J, Zhang C, Wu R, Lin M, Liang Y, Liu J, Wang X, Yang B and Feng Z: RRAD inhibits the Warburg effect through negative regulation of the NF-kB signaling. Oncotarget 6(17): 1498214992, 2015.

28 Shang R, Wang J, Sun W, Dai B, Ruan B, Zhang Z, Yang X, Gao Y, Qu S, Lv X, Tao K, Wang L, Dou K and Wang D: RRAD inhibits aerobic glycolysis, invasion, and migration and is associated with poor prognosis in hepatocellular carcinoma. Tumour Biol 37(4): 5097-5105, 2016.

29 Zhang C, Liu J, Wu R, Liang Y, Lin M, Liu J, Chan CS, Hu W and Feng Z: Tumor suppressor p53 negatively regulates glycolysis stimulated by hypoxia through its target RRAD: Oncotarget 5(14): 5535-5546, 2014.

30 Sándor N, Schilling-Tóth B, Kis E, Benedek A, Lumniczky K, Sáfrány $\mathrm{G}$ and Hegyesi $\mathrm{H}$ : Growth Differentiation Factor-15 (GDF-15) is a potential marker of radiation response and radiation sensitivity. Mutat Res Genet Toxicol Environ Mutagen 793: 142-149, 2015.

31 Park H, Kim $\mathrm{CH}$, Jeong JH, Park $\mathrm{M}$ and Kim KS: GDF15 contributes to radiation-induced senescence through the ROSmediated p16 pathway in human endothelial cells. Oncotarget 7(9): 9634-9644, 2016.

32 Schiegnitz E, Kämmerer PW, Rode K, Schorn T, Brieger J and Al-Nawas B: Growth differentiation factor 15 as a radiationinduced marker in oral carcinoma increasing radiation resistance. J Oral Pathol Med 45(1): 63-69, 2016.

33 Mobasheri MB, Shirkoohi R and Modarressi MH: Cancer/testis OIP5 and TAF7L genes are up-regulated in breast cancer. Asian Pac J Cancer Prev 16(11): 4623-4628, 2015.

34 Hedegaard M, Hansen KB, Andersen KT, Bräuner-Osborne H, Traynelis SF: Molecular pharmacology of human NMDA receptors. Neurochem Int 61(4): 601-609, 2012.

35 Bravatà V, Minafra L, Forte GI, Cammarata FP, Russo G, Di Maggio FM, Augello G, Lio D and Gilardi MC: Cytokine profile of breast cell lines after different radiation doses. Int J Radiat Biol 93(11): 1217-1226, 2017.

36 Di Maggio FM, Minafra L, Forte GI, Cammarata FP, Lio D, Messa C, Gilardi MC and Bravatà V: Portrait of inflammatory response to ionizing radiation treatment. J Inflamm 12: 14, 2015.

Received February 27, 2018

Revised March 27, 2018

Accepted April 3, 2018 